\title{
Estudo de criação e validação de tecnologia educativa para a saúde do pescador artesanal
}

\author{
Study of creation and validation of educational \\ technology for the health of artisanal fishermen
}

\begin{abstract}
Elaine da Silva Abreu', Carlos Alberto Cavalcante Gomes', Eliabe Aguiar da Costa², Isabelle Cristine Sousa Freires', Marina Vasconcelos Souza', Railza Calderaro Gato', Daliane Ferreira Marinho'
\end{abstract}

'Universidade do Estado do Pará, Santarém (PA), Brasil.

${ }^{2}$ Universidade da Amazônia, Santarém (PA), Brasil.

\section{RESUMO}

Objetivo: Criar uma tecnologia educativa e verificar a validação de conteúdo e aparente, referente ao autocuidado em saúde do pescador artesanal. Método: Estudo de desenvolvimento metodológico de criação e validação de tecnologia educativa, realizada no município de Santarém-Pará, no período de fevereiro a setembro de 2020. A criação da tecnologia educativa foi baseada na literatura científica. Na validação de conteúdo participaram 13 juízes especialista, e na aparente, 11 pescadores artesanais, que responderam a um questionário com 3 e 5 blocos, respectivamente. Para a estatística, foi calculado o Índice de Validade de Conteúdo por meio do software BioEstat 5.3. Resultados: O Índice de Validade de Conteúdo de cada blogo e global dos questionários alcançaram um valor acima do proposto pelo estudo. Conclusão: A tecnologia educativa produzida possui validade estatística do seu conteúdo por juízes especialistas e pescadores artesanais.

Palavras-chave: Tecnologia educacional. Saúde. Pesca. Estudo de validação. Saúde do trabalhador.

\begin{abstract}
Objective: To create an educational technology and verify the content and apparent validation, referring to self-care in the health of artisanal fishermen. Methods: Study of methodological development of creation and validation of content and apparent educational technology, carried out in the city of Santarém-Pará, between February and September, 2020. The creation of educational technology was based on scientific literature. In the content validation, 13 expert judges participated, and in the apparent one, 11 artisanal fishermen, who answered a questionnaire with 3 and 5 blocks, respectively. For statistics, the Content Validity Index was calculated using the BioEstat 5.3 software. Results: The Content Validity Index for each block and global of the questionnaires reached a value above the one proposed by the study. Conclusion: The educational technology produced has statistical validity of its content by specialists and target population.
\end{abstract}

Keywords: Educational technology. Health. Fisheries. Validation study. Occupational health.

Recebido: Nov. 05,2020 Aceito: Maio 03, 202

\section{COMO CITAR ESTE ARTIGO}

Abreu ES, Gomes CAC, Costa EA Estudo de criação e validação de tecnologia educativa para a saúde do pescador artesanal. Interdisciplinary Journal of Health Education. 2021 Mês-Mês;6(1): 1-10. https:// doi.org/10.4322/ijhe.2021.009

\section{CORRESPONDÊNCIA}

Elaine da Silva Abreu

Universidade do Estado do Pará

Av. Plácido de Castro, 1399, Aparecida,

Campus XII, CEP 68040-090, Santarém

(PA), Brasil

elainemagalhaes.bel@gmail.com

\section{FONTE DE FINANCIAMENTO}

Nenhuma.

\section{CONFLITO DE INTERESSE}

Os autores declararam não

haver conflitos de interesse.

O estudo foi realizado na Colônia de

Pescadores Z-20, Santarém (PA), Brasil.

Todos os autores leram e aprovam

a versão final submetida ao

Interdisciplinary Journal of

Health Education (IJHE). 


\section{Introdução}

Os pescadores classificados como trabalhadores artesanais, constituem grande contingente e estão, frequentemente, sem acesso aos serviços de saúde do trabalhador. É visto que o trabalho da pesca os expõe aos mais diversos tipos de agravos à saúde, sendo necessário reconhecer a relação entre condições de trabalho, doenças e acidentes de trabalho deste público'1.

Também, é evidenciado a escassez de informações sobre doenças, acidentes de trabalho e a respectiva vigilância epidemiológica e sanitária, principalmente devido ao pouco acesso aos serviços de diagnósticos e reconhecimento de doenças do trabalho. E como agravante, se tem o isolamento social e demográfico dessas populações dos centros de saúde².

Diante das peculiaridades e dificuldades do processo de assistência e educação em saúde com populações gerais e específicas, os profissionais de saúde podem utilizar materiais educativos que potencializam o processo de ensino-aprendizagem em saúde ${ }^{3}$.

Nesse sentido, a Tecnologia Educativa (TE) é um instrumento disponível que tem como intuito facilitar o processo de aprendizagem, traduzindo de forma objetiva as informações essenciais, possibilitando o desenvolvimento de capacidades para o cuidado durante as ações educativas em saúde 4 .

Materiais socioeducativos impressos ampliam a possibilidade de comunicação entre os interessados. A elaboração é precedida pela ampla revisão da literatura e aproximação do público-alvo. Devem ser observados o conteúdo abordado, a linguagem, ilustrações e a diagramação e, também, considerar as barreiras socioculturais, principalmente associadas ao nível de escolaridade ${ }^{5}$. Nesse sentido, a cartilha se revela como facilitadora do processo educativo em saúde, contribuindo nas intervenções voltadas para a necessidade da população abordada ${ }^{6}$.

Assim, diante da problemática da saúde dos pescadores artesanais, ressalta-se a importância da abordagem assistencial e educacional em saúde para este público, incluindo a criação e validação de materiais educativos. Portanto, o presente estudo tem como objetivos criar uma tecnologia educativa do tipo cartilha e verificar a validação de conteúdo e aparente referente ao autocuidado em saúde do pescador artesanal.

\section{Métodos}

\section{Aspectos éticos}

A pesquisa foi aprovada pelo Comitê de Ética da Universidade do Estado do Pará (UEPA), Campus XII, CAAE 28347619.3.0000.5168, com parecer consubstanciado de número 3.835.125, respeitando as normas de pesquisa que envolve seres humanos (Res.466/12 CNS) do Conselho Nacional de Saúde. O Termo de Consentimento Livre e Esclarecido (TCLE) foi assinado por todos os participantes incluídos no estudo.

\section{Desenho, local e período do estudo}

Trata-se de um estudo com abordagem metodológica, quantitativo, divido em duas fases: produção e validação de conteúdo e aparente de uma TE do tipo cartilha. A pesquisa foi realizada no município de Santarém, Pará, no período de fevereiro a setembro de 2020 .

Fases do estudo

\section{Fase de produção da cartilha}

Para compor a amostra da primeira versão da TE foi realizado uma busca na literatura de artigos com evidências científicas publicados em revistas indexadas nas 
principais bases de dados, através dos descritores: Saúde, Pesca, Saúde do Trabalhador, Tecnologia Educacional, Autocuidado. Após a seleção, foram incluídos 12 artigos.

Posteriormente foi produzido as ilustrações, layout e apresentação estrutural da TE, sendo estas realizadas por profissionais capacitados e com experiência na área do design gráfico.

\section{Fase de validação}

Foram convidados profissionais da saúde de nível superior com conhecimento especializado na área e atuantes na assistência no município. O convite foi enviado via e-mail, juntamente com uma carte convite, TCLE, questionário de avaliação e a cartilha em formato digital. O prazo estipulado para devolução ao pesquisador foi de 15 dias.

A inclusão no estudo levou em consideração a busca pelo currículo Lattes para confirmação de ao menos dois dos critérios: Ter titulação de pós-graduação lato sensu, ter produção científica nos últimos dois anos e ter no mínimo dois anos de experiência nas áreas desejadas.

Para a coleta de dados da validação de conteúdo, foi elaborado um questionário, que constava de uma parte inicial com dados descritivos dos juízes, e, para a validação de conteúdo, 19 itens foram incluídos, sendo eles: Objetivos da cartilha; Estrutura e apresentação; Evidência a relevância; Comentários subjetivos do participante.

A validação aparente ocorreu com a participação dos pescadores, o convite ocorreu de forma aleatória na sede da Colônia de Pescadores Z-20, no município de Santarém, onde foi disponibilizado a carta convite, o TCLE, questionário de avaliação e cartilha impressa. Sendo os seguintes critérios de inclusão: pescadores de ambos os sexos, com idade igual ou superior a 18 anos, associados a colônia de pescadores Z-20, estar em plena atividade de trabalho e capacidade de leitura.

O questionário de coleta de dados dos pescadores também constou com dados descritivos, e para validação, seis tópicos foram avaliados, sendo: Objetivos da cartilha; Organização geral; Características linguísticas; Aparência; Avaliação motivacional; Comentários subjetivos do participante. Ao todo, os pescadores avaliaram 25 itens. Ademais, foi levado em consideração as sugestões nas avaliações, com o objetivo de aprimoramento da versão final da TE.

Os questionários foram estruturados conforme a escala de Likert $^{7}$, uma técnica de classificação que contem quatro graus de valorização: totalmente adequada (TA), adequada (A), parcialmente adequada (PA) e inadequada (I). Os graus TA e A são considerados concordantes para a validação.

\section{Análise dos dados}

Os dados dos questionários foram submetidos a análises estatística dos resultados com uso dos programas Microsoft Excel 2010 e BioEstat5.3 ${ }^{\circledR}$. A análise quantitativa da validação foi feita por meio do Índice de Validade de Conteúdo (IVC), que mede a proporção da concordância sobre determinado assunto em um instrumento. Buscou-se obter a média de cada item e, para a validação global da TE, a somatória de todos os IVC separadamente, dividido pelo número de itens do instrumento. Nesta pesquisa foi considerado o valor de concordância, dos juízes especialistas e dos pescadores artesanais, superior a $0.78^{8}$, recomendado quando há mais de seis avaliadores. Para os valores abaixo, são feitos reajustes dos itens do instrumento.

\section{Resultados}

Até a fase de produção da versão final da TE, foram desenvolvidas 3 versões, sendo a versão final apresentada em papel opaline, de dimensões $21 \mathrm{~cm} \times 14.80 \mathrm{~cm}$, contendo 26 páginas, composta por capa, fixa técnica, sumário, apresentação e 
páginas do conteúdo com textos e ilustrações. A Figura 1 demonstra algumas seções do material impresso.

O título e subtítulo incluídos foram: "Cartilha da saúde do pescador artesanal" "Orientações para o autocuidado no trabalho de pesca artesanal", respectivamente. Os temas abordados foram: "Você sabe o que é saúde?"; "O que é risco à saúde"; "Riscos do ambiente";; "Câncer de pele"; "Acidentes com animais e objetos cortantes"; "Acidentes dentro e fora da embarcação"; "Escalpelamento"; "Dores relacionadas ao trabalho"; "O que são as dores nas costas e lombalgias?"; "Posturas comuns na atividade de pesca"; "Exercícios de alongamentos e relaxamento"; "Cuidados com uso de tabaco e consumo de bebidas alcóolicas"; "Fique por dentro".
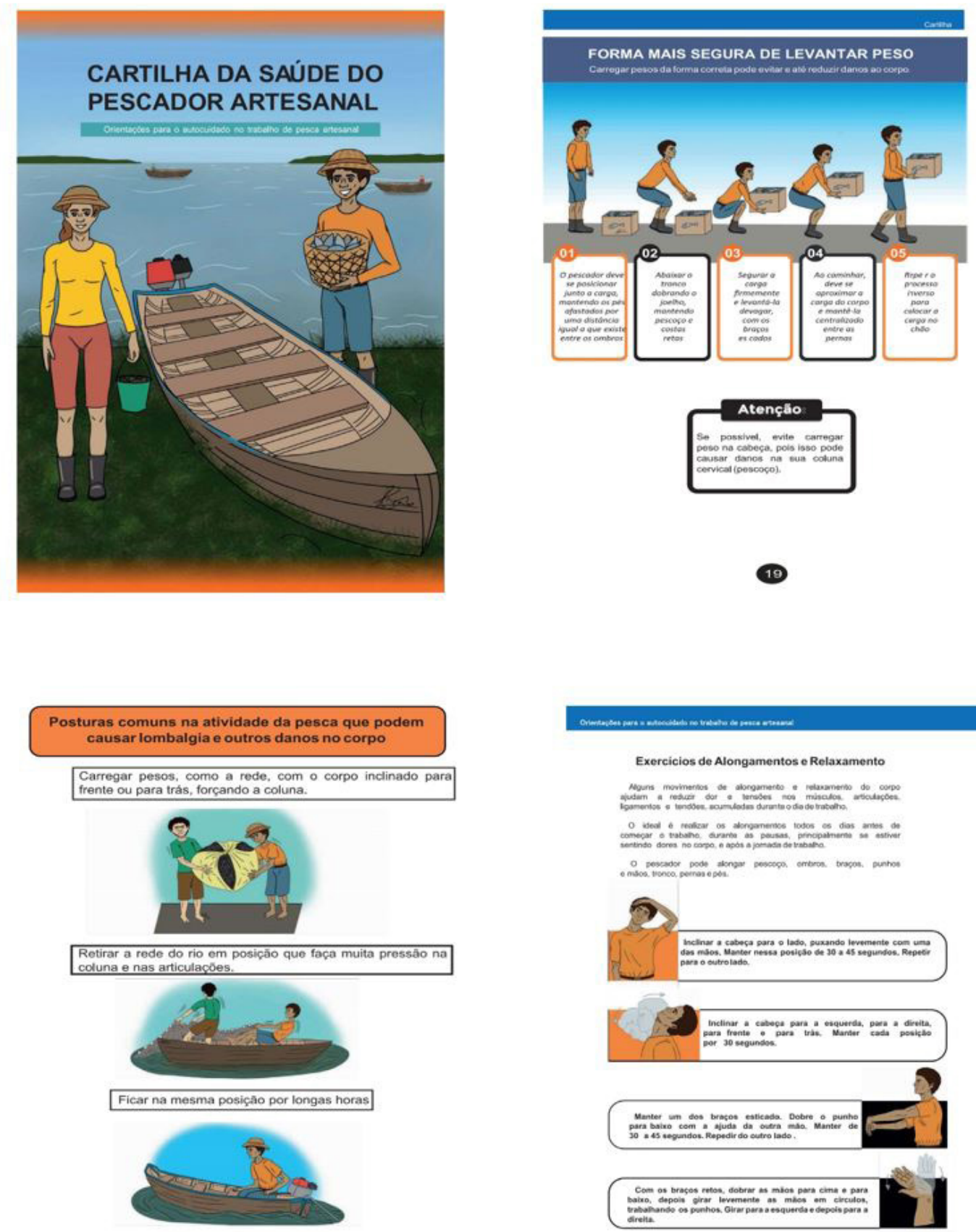

18

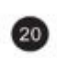

Figura 1. Seções da cartilha.

Fonte: Dados da pesquisa (2020). 
Para o procedimento de validação de conteúdo, foram convidados 15 juízes especialistas, sendo que 13 devolveram o material em tempo hábil e foram incluídos na amostra do estudo. Dos 13 juízes especialistas, 7 (53,8\%) eram fisioterapeutas, 4 (30,7\%) enfermeiros e $2(15,3 \%)$ terapeutas ocupacionais. 69,2\% dos juízes eram do sexo feminino. A idade média foi de 29,9 anos $( \pm 8,63)$. Quanto a titulação, 2 possuíam doutorado, 1 mestrado e 10 especialização.

Como exposto na Tabela 1, em relação ao bloco objetivos, foi alcançado um nível de concordância de 98,07\% (somatória de TA e A) e IVC do bloco 0.98. Na avaliação do bloco estrutura e apresentação verificou-se um nível de concordância de 81,12\%. Na avaliação do IVC por item houveram duas médias de 0.53 e uma de 0.61. Já o IVC do bloco foi de 0.80 . Para o bloco relevância houve uma concordância de $96,14 \%$ e IVC do bloco de 0.96. O IVC Global da validação de conteúdo foi de 0.87 , estando, portanto, acima da concordância mínima de 0.78 .

Tabela 1. Validação de conteúdo pelos juízes especialistas quanto aos itens da cartilha.

\begin{tabular}{|c|c|c|c|c|c|}
\hline \multirow{2}{*}{ Itens } & \multicolumn{3}{|c|}{$\mathbf{N}=13$} & \multicolumn{2}{|c|}{$\mathrm{TA}+\mathrm{A} \times 100 / \mathbf{N}$} \\
\hline & TA & $\mathbf{A}$ & PA & I & IVC \\
\hline \multicolumn{6}{|l|}{1 Bloco Objetivos } \\
\hline 1.1 Importância do conteúdo & 12 & 1 & 0 & 0 & 1 \\
\hline $\begin{array}{l}1.2 \text { Incentiva mudança de } \\
\text { comportamento }\end{array}$ & 5 & 8 & 0 & 0 & 1 \\
\hline 1.3 Pode circular no meio científico & 9 & 3 & 1 & 0 & 0,92 \\
\hline $\begin{array}{l}\text { 1.4 Atende aos objetivos de atenção ao } \\
\text { pescador artesanal }\end{array}$ & 11 & 2 & 0 & 0 & 1 \\
\hline Escore por bloco & 37 & 14 & 1 & 0 & \\
\hline Percentual por bloco & 71,15 & 26,92 & 1,92 & 0 & \\
\hline Total dos percentuais & & & 99,99 & & \\
\hline IVC Bloco & & & 0,98 & & \\
\hline \multicolumn{6}{|l|}{2 Bloco Estrutura e Apresentação } \\
\hline $\begin{array}{l}2.1 \text { A cartilha está apropriada para o } \\
\text { pescador artesanal }\end{array}$ & 8 & 3 & 2 & 0 & 0,84 \\
\hline $\begin{array}{l}2.2 \text { As informações são claras e } \\
\text { objetivas }\end{array}$ & 2 & 9 & 2 & 0 & 0,84 \\
\hline $\begin{array}{l}2.3 \text { O material está apropriado para } \\
\text { todo nível sociocultural }\end{array}$ & 12 & 1 & 0 & 0 & 1 \\
\hline 2.4 Há sequência lógica de pensamento & 2 & 5 & 5 & 1 & 0,53 \\
\hline $\begin{array}{l}2.5 \text { Concordância ortográfica e } \\
\text { linguagem acessível }\end{array}$ & 10 & 3 & 0 & 0 & 1 \\
\hline $\begin{array}{l}\text { 2.6 Estilo de redação compatível ao } \\
\text { nível de conhecimento do leitor }\end{array}$ & 4 & 3 & 4 & 2 & 0,53 \\
\hline $\begin{array}{l}\text { 2.7 Coerência nas informações de capa, } \\
\text { sumário e apresentação }\end{array}$ & 4 & 4 & 5 & 0 & 0,61 \\
\hline $\begin{array}{l}\text { 2.8 Fonte da letra utilizada está } \\
\text { apropriada para leitura }\end{array}$ & 10 & 3 & 0 & 0 & 1 \\
\hline $\begin{array}{l}\text { 2.9 As ilustrações são expressivas e } \\
\text { complementares ao texto }\end{array}$ & 8 & 3 & 1 & 1 & 0,84 \\
\hline $\begin{array}{l}\text { 2.10 As informações são cientificamente } \\
\text { corretas }\end{array}$ & 4 & 7 & 2 & 0 & 0,84 \\
\hline
\end{tabular}

Legenda: TA = Totalmente adequado; A = Adequado; PA = Parcialmente adequado; I = Inadequado; IVC = Índice de Validade de Conteúdo. Fonte: Dados da pesquisa (2020). 
Tabela 1. Continuação...

\begin{tabular}{|c|c|c|c|c|c|}
\hline \multirow{2}{*}{ Itens } & \multicolumn{3}{|c|}{$\mathbf{N}=13$} & \multicolumn{2}{|c|}{$\mathrm{TA}+\mathrm{Ax} \mathbf{x} 100 / \mathrm{N}$} \\
\hline & TA & $\mathbf{A}$ & PA & I & IVC \\
\hline $\begin{array}{l}2.11 \text { O número de páginas está } \\
\text { adequado }\end{array}$ & 6 & 5 & 2 & 0 & 0,84 \\
\hline Escore por bloco & 70 & 46 & 23 & 4 & \\
\hline Percentual por bloco & 48,95 & 32,17 & 16,08 & 2,19 & \\
\hline Total dos percentuais & & & 99,99 & & \\
\hline IVC Bloco & & & 0,8 & & \\
\hline \multicolumn{6}{|l|}{3 Bloco Relevância } \\
\hline $\begin{array}{l}\text { 3.1 São abordados os aspectos chave } \\
\text { para o autocuidado }\end{array}$ & 11 & 2 & 0 & 0 & 1 \\
\hline $\begin{array}{l}\text { 3.2 Permite a transferência de } \\
\text { informações no ambiente da pesca }\end{array}$ & 7 & 5 & 1 & 0 & 0,92 \\
\hline $\begin{array}{l}\text { 3.3 Propõe a mudança de } \\
\text { comportamento e aquisição de } \\
\text { conhecimento }\end{array}$ & 8 & 5 & 0 & 0 & 1 \\
\hline $\begin{array}{l}\text { 3.4 Aborda os temas necessário para o } \\
\text { saber do pescador artesanal }\end{array}$ & 9 & 3 & 1 & 0 & 0,92 \\
\hline Escore por bloco & 35 & 15 & 2 & 0 & \\
\hline Percentual por bloco & 67,3 & 28,84 & 3,84 & 0 & \\
\hline Total dos percentuais & & & 99,98 & & \\
\hline IVC Bloco & & & 0,96 & & \\
\hline IVC Global & & & 0,87 & & \\
\hline
\end{tabular}

Legenda: TA = Totalmente adequado; $\mathrm{A}$ = Adequado; $\mathrm{PA}=$ Parcialmente adequado; $\mathrm{I}=$ Inadequado; $\mathrm{IVC}=$ Índice de Validade de Conteúdo. Fonte: Dados da pesquisa (2020).

Analisando o número total das respostas de valorização do escore dos itens da TE, foi apontado um total de 142 (57,48\%) para TA e 75 (30,36\%) para A. Assim, é demonstrado uma concordância para a maioria dos itens. Ademais, dos 19 itens avaliados, apenas 3 receberam grau I (inadequado). Dessa forma, os itens 2.4, $2.6 \mathrm{e}$ 2.7, por não terem alcançado o índice mínimo, foram revisados.

Para os resultados da validação aparente, 15 pescadores artesanais foram convidados, sendo que 11 foram incluídos na amostra final do estudo. $81,81 \%$ dos pescadores eram do sexo masculino. A idade média foi de 43,3 anos ( \pm 6$)$. Quanto ao tempo de iniciação na atividade de pesca, a média foi de 26,8 anos $( \pm 9,62)$. Para a escolaridade, $54,54 \%$ possui ensino fundamental incompleto, 27,27\% ensino fundamental completo, 9,09\% ensino médio incompleto e $9,09 \%$ ensino médio completo. No que se refere a principal atividade durante a pesca, $100 \%$ dos participantes citaram a captura do pescado.

A Tabela 2 apresenta os resultados da validação aparente. Para o bloco objetivos, o índice de concordância foi de $100 \%$ e o IVC do bloco 1. Já o bloco organização apresentou uma concordância de $98,7 \%$, e IVC para o bloco de 0.98 . No bloco a avaliação das características linguísticas, foi atribuído um nível de concordância de 98,47\%, e o IVC foi de 0.98 para o bloco. No bloco aparência, organização e ilustrações, a concordância foi de $100 \%$, portanto um IVC de bloco de 1. E por último, na validação da capacidade de provocar impacto no leito, houve um nível de concordância de $100 \%$ e IVC de 1 para o bloco.

O IVC Global da validação aparente foi de 0.99. Além disso, ficou evidenciado uma alta concordância, visto que dos 275 itens avaliados pelos pescadores artesanais, todos 
Tabela 2. Validação aparente pelos pescadores artesanais quanto aos itens da cartilha.

\begin{tabular}{|c|c|c|c|c|c|}
\hline \multirow{2}{*}{ Itens } & \multirow{2}{*}{ TA } & \multicolumn{2}{|c|}{$\mathbf{N}=\mathbf{1 1}$} & \multirow{2}{*}{ I } & \multirow{2}{*}{$\begin{array}{c}\mathrm{TA}+\mathrm{Ax} 100 / \mathrm{N} \\
\text { IVC }\end{array}$} \\
\hline & & $\mathbf{A}$ & PA & & \\
\hline \multicolumn{6}{|l|}{1 Bloco Objetivos } \\
\hline $\begin{array}{l}\text { 1.1 Entendimento para que serve } \\
\text { a cartilha }\end{array}$ & 10 & 1 & 0 & 0 & 1 \\
\hline $\begin{array}{l}1.2 \text { A cartilha vai auxiliar no } \\
\text { autocuidado }\end{array}$ & 11 & 0 & 0 & 0 & 1 \\
\hline $\begin{array}{l}\text { 1.3 A cartilha é adequada para } \\
\text { ser usada na pesca artesanal }\end{array}$ & 7 & 4 & 0 & 0 & 1 \\
\hline Escore por bloco & 28 & 5 & 0 & 0 & \\
\hline Percentual por bloco & 84,84 & 15,15 & 0 & 0 & \\
\hline Total dos percentuais & & & 99,99 & & \\
\hline IVC Bloco & & & 1 & & \\
\hline \multicolumn{6}{|l|}{2 Bloco Organização } \\
\hline $\begin{array}{l}2.1 \text { A capa está atraente e indica } \\
\text { o conteúdo }\end{array}$ & 10 & 1 & 0 & 0 & 1 \\
\hline $\begin{array}{l}2.2 \text { A fonte da letra está } \\
\text { adequada }\end{array}$ & 10 & 1 & 0 & 0 & 1 \\
\hline $\begin{array}{l}2.3 \text { Há sequência lógica entre os } \\
\text { tópicos }\end{array}$ & 8 & 3 & 0 & 0 & 1 \\
\hline $\begin{array}{l}2.4 \text { Há entendimento entre capa, } \\
\text { sumário e apresentação }\end{array}$ & 6 & 5 & 0 & 0 & 1 \\
\hline $\begin{array}{l}2.5 \text { O papel impresso está } \\
\text { adequado }\end{array}$ & 7 & 3 & 1 & 0 & 0,90 \\
\hline $\begin{array}{l}2.6 \text { O número de páginas está } \\
\text { adequado }\end{array}$ & 9 & 2 & 0 & 0 & 1 \\
\hline $\begin{array}{l}2.7 \text { Os temas trazem informações } \\
\text { importantes }\end{array}$ & 11 & 0 & 0 & 0 & 1 \\
\hline Escore por bloco & 61 & 15 & 1 & 0 & \\
\hline Percentual por bloco & 79,22 & 19,48 & 1,29 & 0 & \\
\hline Total dos percentuais & & & 99,99 & & \\
\hline IVC Bloco & & & 0,98 & & \\
\hline \multicolumn{6}{|l|}{$\begin{array}{l}3 \text { Bloco Características } \\
\text { linguísticas }\end{array}$} \\
\hline $\begin{array}{l}\text { 3.1 A escrita está em estilo que } \\
\text { facilita o entendimento }\end{array}$ & 9 & 2 & 0 & 0 & 1 \\
\hline $3.2 \mathrm{O}$ texto é interessante & 11 & 0 & 0 & 0 & 1 \\
\hline $\begin{array}{l}3.3 \text { O vocabulário é de fácil } \\
\text { compreensão }\end{array}$ & 6 & 5 & 0 & 0 & 1 \\
\hline $\begin{array}{l}\text { 3.4 Há associado do tema } \\
\text { de cama sessão ao texto } \\
\text { correspondente }\end{array}$ & 8 & 3 & 0 & 0 & 1 \\
\hline $3.5 \mathrm{O}$ texto está claro & 7 & 4 & 0 & 0 & 1 \\
\hline $\begin{array}{l}\text { 3.6 O estilo da redação } \\
\text { corresponde ao nível de } \\
\text { conhecimento }\end{array}$ & 3 & 7 & 1 & 0 & 0,90 \\
\hline Escore por bloco & 44 & 21 & 1 & $\mathrm{o}$ & \\
\hline Percentual por bloco & 66,66 & 31,81 & 1,51 & 0 & \\
\hline
\end{tabular}

Legenda: TA = Totalmente adequado; $\mathrm{A}$ = Adequado; $\mathrm{PA}$ = Parcialmente adequado; $\mathrm{I}=$ Inadequado; $\mathrm{IVC}=$ Índice de Validade de Conteúdo. Fonte: Dados da pesquisa (2020). 
Tabela 2. Continuação...

\begin{tabular}{|c|c|c|c|c|c|}
\hline \multirow{2}{*}{ Itens } & \multirow{2}{*}{ TA } & \multicolumn{2}{|c|}{$\mathrm{N}=\mathbf{1 1}$} & \multirow{2}{*}{ I } & \multirow{2}{*}{$\begin{array}{c}\mathrm{TA}+\mathrm{A} \times 100 / \mathrm{N} \\
\text { IVC }\end{array}$} \\
\hline & & $\mathbf{A}$ & PA & & \\
\hline Total dos percentuais & & & 99,98 & & \\
\hline IVC Bloco & & & 0,98 & & \\
\hline \multicolumn{6}{|l|}{4 Bloco Aparência } \\
\hline 4.1 As páginas estão organizadas & 11 & 0 & 0 & 0 & 1 \\
\hline $\begin{array}{l}\text { 4.2 A ilustrações são de fácil } \\
\text { entendimento }\end{array}$ & 11 & 0 & 0 & 0 & 1 \\
\hline $\begin{array}{l}\text { 4.3 As ilustrações } \\
\text { complementam os textos }\end{array}$ & 11 & 0 & 0 & 0 & 1 \\
\hline $\begin{array}{l}\text { 4.4 As ilustrações estão } \\
\text { expressivas o suficiente }\end{array}$ & 11 & 0 & 0 & 0 & 1 \\
\hline Escore por bloco & 44 & 0 & 0 & 0 & \\
\hline Percentual por bloco & 100 & 0 & 0 & 0 & \\
\hline Total dos percentuais & & & 100 & & \\
\hline IVC Bloco & & & 1 & & \\
\hline \multicolumn{6}{|l|}{5 Bloco Motivação } \\
\hline $\begin{array}{l}\text { 5.1 A cartilha está adequada ao } \\
\text { leito }\end{array}$ & 10 & 1 & 0 & 0 & 1 \\
\hline $\begin{array}{l}5.2 \text { Os conteúdos são } \\
\text { apresentados de forma clara }\end{array}$ & 10 & 1 & 0 & 0 & 1 \\
\hline $\begin{array}{l}5.3 \text { Os assuntos são importantes } \\
\text { para o autocuidado na pesca }\end{array}$ & 10 & 1 & 0 & 0 & 1 \\
\hline $\begin{array}{l}5.4 \text { A cartilha instiga mudança } \\
\text { de comportamento }\end{array}$ & 11 & 0 & 0 & 0 & 1 \\
\hline $\begin{array}{l}5.5 \text { A cartilha apresenta } \\
\text { conhecimentos para o pescador }\end{array}$ & 11 & 0 & 0 & 0 & 1 \\
\hline Escore por bloco & 52 & 3 & 0 & 0 & \\
\hline Percentual por bloco & 94,54 & 5,45 & 0 & 0 & \\
\hline Total dos percentuais & & & 99,99 & & \\
\hline IVC Bloco & & & 1 & & \\
\hline IVC Global & & & 0,99 & & \\
\hline
\end{tabular}

Legenda: TA = Totalmente adequado; A = Adequado; PA = Parcialmente adequado; I = Inadequado; IVC = Índice de Validade de Conteúdo. Fonte: Dados da pesquisa (2020).

se mostraram adequados, alcançando o objetivo do estudo. Ademais, as sugestões feitas pelos juízes especialistas e pescadores artesanais estão dispostas no Quadro 1.

\section{Discussão}

O uso da TE abordada nesse estudo se justificou frente a importância de se trabalhar com alternativas que possibilitem a promoção da saúde dos pescadores artesanais. A utilização de TE validada ${ }^{9}$ atribui maior qualidade ao processo de ensino e aprendizagem, sendo importante para o público trabalhado e para o profissional educador.

A TE do presente estudo foi validada por juízes especialistas e pescadores artesanais, alcançando índices de concordância satisfatórios e IVC global de 0.87 e 0.99 na validação de conteúdo e aparente, respectivamente. Em concordância com 
Quadro 1. Sugestões feitas na validação de conteúdo e aparente.

\begin{tabular}{|l|}
\hline Substituição de termos técnicos \\
\hline Correção ortográfica \\
\hline Reduzir número de páginas \\
\hline Reduzir extensão dos textos \\
\hline Aumentar o tamanho da letra \\
\hline Incluir informações sobre acidentes causados por ventanias \\
\hline Aumentar o número de ilustrações \\
\hline
\end{tabular}

os resultados encontrados, estudo desenvolvido com a mesma metodologia, com juízes multiprofissionais, encontrou índice de concordância elevado, apresentando IVC de $0.96^{10}$.

O procedimento de validação permitiu um aprimoramento do conteúdo e de apresentação da TE para uma disponibilização final mais fiel ao público. Achados da literatura apontam ${ }^{11}$ que a metodologia utilizada se mostrou adequada para o processo de construção e validação de TE.

Foi possível observar nos resultados da validação pelos juízes especialistas que os itens menos concordantes se relacionavam a compatibilidade da escrita com o nível de conhecimento do público alvo. Além do mais, a importância da adequação da compatibilidade de leitura se confirmou quando foi analisado neste estudo o nível de escolaridade dos pescadores artesanais, em que $54,54 \%$ possui ensino fundamental incompleto. Assim, a metodologia de correções desses itens buscou torná-los o mais acessível possível a leitura da cartilha.

Para que a informação atenda ao objetivo a que se propõe ao leitor, as TE em saúde requer o seguimento de pré-requisitos metodológicos de seleção e apresentação didática de conteúdo e linguagem que contribuam para uma melhor assimilação da informação para possibilitar o desenvolvimento de atitudes e habilidades que influenciam seu padrão de saúde ${ }^{9,12}$.

$\mathrm{Na}$ fase de produção da TE, as temáticas abordadas e os aspectos chave para o autocuidado do pescador artesanal foram considerados adequados, apresentando alto grau de concordância entre os juízes especialistas. Estudo de validação semelhante confirma ${ }^{13}$ a importância do processo de validação feita por juízes especialista para a definição dos temas que serão introduzidos na TE.

No processo de construção da TE buscou-se incluir os principais riscos aos quais os pescadores artesanais estão expostos, de acordo com a literatura científica pesquisada, incluindo os fatores ambientais, os laborais e comportamentais. Também foram sugeridas medidas de prevenção de acidentes e tomadas de decisão frente a um ocorrido, além de promoção da saúde.

O objetivo alcançado da validação da TE busca disponibilizar um material capaz contribuir para o autocuidado em saúde do pescador artesanal. É visto que a utilização de materiais educativos é capaz de aprimorar os conhecimentos e estimular a tomada de atitudes pelos leitores ${ }^{14}$.

Como limitações deste estudo, pode-se citar o cenário de distanciamento social necessário frente a pandemia da COVID-19, que impossibilitou a realização de visitas às localidades dos pescadores de Santarém, e assim, conhecer as necessidades relatadas pelo público. Também se reconhece o desafio de produzir uma TE com linguagem simplificada e didáticas para públicos com baixo nível de escolaridade.

Também, é de grande importância verificar, posteriormente, a efetividade da implantação do uso da TE produzida durante o cuidado do pescador artesanal. Ademais, é ressaltada a importância de novos estudos que abordem os múltiplos fatores relacionados à atividade de pesca e que incluam o desenvolvimento de tecnologias para o auxílio na prevenção, promoção e reabilitação da saúde do pescador artesanal. 


\section{Conclusão}

Os resultados deste estudo permitem afirmar que a TE produzida possui validade estatística do seu conteúdo por juízes especialistas e pescadores. Assim, a presente cartilha configura-se como uma ferramenta importante e útil para promoção de saúde dos pescadores artesanais da região do Baixo Amazonas.

O procedimento de construção da TE permitiu conhecer a realidade dos pescadores artesanais do Pará, em especial da região do Baixo Amazonas, e evidenciou a necessidade de se buscar alternativas em saúde que atendam as especificidades das populações tradicionais da Amazônia. Também, abre-se a possibilidade de utilização da TE em outras localidades pesqueiras.

\section{Referências}

1. Rego RF, Muller JS, Falcão IR, Pena PGL. Vigilância em saúde do trabalhador da pesca artesanal na Baía de Todos os Santos: da invisibilidade à proposição de políticas públicas para o Sistema Único de Saúde (SUS). Rev Bras Saúde Ocup. 2018;43(supl 1):e10s. http://dx.doi.org/10.1590/2317-6369000003618.

2. Pena PGL, Martins V, Rego RF. Por uma política para a saúde do trabalhador não assalariado: o caso dos pescadores artesanais e das marisqueiras. Rev Bras Saúde Ocup. 2013;38(127):57-68. http://dx.doi.org/10.1590/S0303-76572013000100009.

3. Moura DJM, Moura NS, Menezes LCG, Barros AA, Guedes MVC. Construção de cartilha sobre insulinoterapia para crianças com diabetes mellitus tipo 1. Rev Bras Enferm. 2017;70(1):7-14. http://dx.doi.org/10.1590/0034-7167-2016-0183. PMid:28226036.

4. Elizabeth TI, Palmeira IP, Rodrigues ILA, Brasil GB, Carvalho DS, Machado TD. Desenvolvimento participativo de tecnologia educacional em contexto hiv/aids. Rev Min Enferm. 2019;23:e-1236. http://dx.doi.org/10.5935/1415-2762.20190084.

5. Mendez SP, Sá KN, Araújo PCS, Oliveira IAVF, Gosling AP, Baptista AF. Desenvolvimento de uma cartilha educativa para pessoas com dor crônica. Rev Dor São Paulo. 2017 jul-set;18(3):199-211. http://dx.doi.org/10.5935/1806-0013.20170103.

6. Santiago JCDS, Moreira TMM. Booklet content validation on excess weight for adults with hypertension. Rev Bras Enferm. 2019;72(1):95-101. http://dx.doi.org/10.1590/0034-7167-2018-0105. PMid:30916273.

7. Nascimento MHM, Teixeira E. Tecnologia educacional para mediar o acolhimento de "familiares cangurus" em unidade neonatal. Rev Bras Enferm. 2018;71(supl 3):1370-7. http://dx.doi.org/10.1590/0034-7167-2017-0156. PMid:29972526.

8. Lynn MR. Determination and quantification of contente validity. Nurs Res. 1986;35(6):382-5. http://dx.doi.org/10.1097/00006199198611000-00017. PMid:3640358.

9. Albuquerque AFLL, Pinheiro AKB, Linhares FMP, Guedes TG. Tecnologia para o autocuidado da saúde sexual e reprodutiva de mulheres estomizadas. Rev Bras Enferm. 2016;69(6):1164-71. http://dx.doi.org/10.1590/0034-7167-2016-0302. PMid:27925094.

10. Gonçalves MS, Celedônio RF, Targino MB, et al. Construção e validação de cartilha educativa para promoção da alimentação saudável entre pacientes diabéticos. Rev Bras Promoç Saúde. 2019;32:7781. http://dx.doi.org/10.5020/18061230.2019.7781.

11. Teixeira E, Martins TDR, Miranda PO, Cabral BG, Costa e Silva BA, Rodrigues LSS. Tecnologia educacional sobre cuidados no pós-parto: construção e validação. Rev Baiana Enferm. 2016; abr-jun;30(2):1-10. http://dx.doi.org/10.18471/ rbe.v30i2.15358.

12. Ximenes MAM, Fontenele NÂO, Bastos IB, et al. Construção e validação de conteúdo de cartilha educativa para prevenção de quedas no hospital. Acta Paul Enferm. 2019;32(4):433-41. http://dx.doi.org/10.1590/1982-0194201900059.

13. Mendez SP, Sá KN, Araújo PC, Oliveira IA, Gosling AP, Baptista AF. Desenvolvimento de uma cartilha educativa para pessoas com dor crônica. Rev Dor. São Paulo, 2017; jul-set;18(3):199-211. https://doi.org/10.5935/1806-0013.20170103.

14. Oliveira SC, Fernandes AF, Vasconcelos EM, et al. Efeito de uma intervenção educativa na gravidez: ensaio clínico randomizado em cluster. Acta Paul Enferm. 2018;31(3):291-8. http://dx.doi.org/10.1590/1982-0194201800041.

\section{Contribuição dos autores}

Elaine da Silva Abreu participou de todas as etapas da pesquisa e da confecção do manuscrito. Eliabe Aguiar da Costa participou da execução do projeto, coleta e tratamento dos dados, análise dos dados e revisão crítica do manuscrito. Marina Vasconcelos Souza contribuiu com o levantamento da literatura, redação e revisão crítica do manuscrito. Carlos Alberto Cavalcante Gomes, Isabelle Cristine Sousa Freires e Railza Calderaro Gato contribuíram com a coleta e tratamento dos dados, análise e interpretação e revisão crítica do manuscrito. Daliane Ferreira Marinho participou no desenvolvimento metodológico, supervisão e revisão crítica do manuscrito. 